\title{
Finite Element Analysis of Fretting Fatigue Fracture in Lug Joints Made of High Strength Steel
}

\author{
Reza Hojjati Talemi ${ }^{1,2, *}$, Jie Zhang ${ }^{3,4}$, Stijn Hertelé ${ }^{3}$, Wim De Waele ${ }^{3}$ \\ ${ }^{1}$ ArcelorMittal Global R\&D Gent-OCAS N.V., Pres. J.F. Kennedylaan 3, 9060 Zelzate, Belgium \\ ${ }^{2}$ Present address: Department of Materials Engineering, KU Leuven, Kasteelpark Arenberg 44, 3001 Leuven, Belgium \\ ${ }^{3}$ Soete Laboratory, Department of Electrical Energy, Metals, Mechanical Constructions and Systems, Ghent University, Belgium \\ ${ }^{4}$ SIM vzw, Technologiepark 935, BE-9052 Zwijnaarde, Belgium
}

\begin{abstract}
Many structural applications are aiming for weight reduction by using high strength steel. In a lug joint the load is transmitted by a pin, which leads to a pressure distribution on the hole in the lug. When a lug joint is subjected to axial cyclic loading conditions, the stress distribution becomes multiaxial, i.e. a combination of normal and tangential stresses. In such loading case, a fretting crack initiates at the contact interface between the pin/lug connection which is followed by a fatigue crack propagation up to the final rupture of the lug. In this study, the fretting fatigue crack initiation and propagation in a pin/lug joint are simulated using multiaxial fatigue criterion and fracture mechanics, respectively. To do so, first a 2D finite element model is developed for obtaining stresses and strains at the contact interface in a pin/lug joint. Using the extracted data, fretting fatigue failure parameters are analysed. Next, the obtained stresses and strains are used to estimate the crack initiation lifetime using a fatigue multiaxial critical plane model. A 3D model is set-up to simulate the crack propagation using eXtended Finite Element Method (XFEM). Eventually, the predicted total fatigue lifetimes are compared against experimental observations taken from literature.
\end{abstract}

\section{Introduction}

The production of lightweight and reliable structures is primarily achieved by using high-strength materials. This special place is occupied by micro-alloyed High Strength Steels (HSS), due to the wide availability of steel as a material, and their cost being significantly more acceptable in comparison to other alternative materials. The use of HSS may reduce the weight, and thus lower the costs of procurement, manufacturing, installation and testing of a steel structure. Nowadays, it is impossible to imagine the construction of mobile and fixed cranes, passenger and freight cars (road or rail), or equipment for mining, without the use of HSS. Given its high strength, and considering the type of structures to be used for, these steels should meet essential mechanical, technological and design requirements.

Namely, the higher the yield stress and tensile strength, design codes are considered to require greater "reserve" in case of overloading, and thus significant plastic strain that would precede the eventual fracture or damage of a structure. Thus, in order to ensure higher safety in the application of HSS, standard tensile and impact tests must be accompanied by appropriate tests in terms of fatigue and fracture mechanics. This is particularly important considering the fact that the highly efficient methods and procedures for the assessment and design of various types of structures, are based on the knowledge of these parameters (Eurocode and so on).

Figure 1 shows a crawler crane in which the counter weight is supported by a steel chain, which consists of a series of high loaded bars made of HSS e.g. S1100Q as reported in [1].

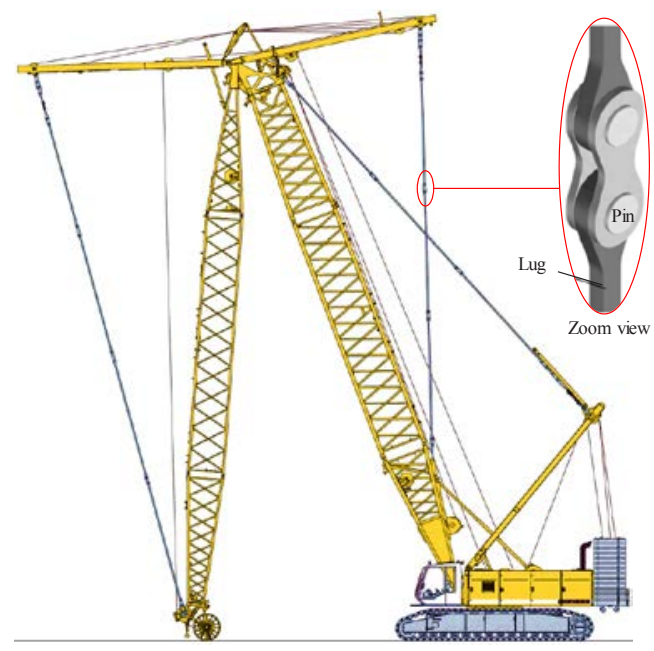

Fig. 1. Schematic view of a crawler crane and pin/lug joint made of HSS. 
The steel chain is made of different pin-lug connections. In a lug joint the load is transmitted by a pin, which leads to a pressure distribution on the hole in the lug. When a lug joint is subjected to axial cyclic loading conditions, the cyclic stress distribution becomes multiaxial, i.e. a combination of normal and tangential stresses. In such loading case, a fretting crack may initiate at the contact interface between the pin/lug connection which is followed by fatigue crack propagation up to the final rupture of the lug. This phenomenon is known as fretting fatigue failure, and is well documented in literature for different applications such as automotive industry [2, 3], bolted and riveted connections [4, 5], steel cables, bearing shafts and steam/gas turbines. Fretting fatigue may reduce the lifetime of a component by half or even more, in comparison to plain fatigue [6]. This reduction is due to a complex multiaxial and non-proportional stress state which occurs at a contact interface under partial slip loading conditions [7-10]. Therefore, it is very important to understand the underlying failure mechanism. This goal could be achieved by separating the failure process into different stages, and subsequently estimating the fretting fatigue crack initiation and fatigue crack propagation lifetimes from the final lifetime.

In this study, the fretting fatigue crack initiation and propagation in a pin/lug joint are simulated using a multiaxial fatigue criterion and fracture mechanics, respectively. To do so, first a $2 \mathrm{D}$ plane strain finite element model is developed for obtaining stresses and strains at the contact interface in a pin/lug joint. Using the calculated stress distributions, fretting fatigue failure parameters are analysed. Next, the extracted data are used to estimate the fatigue crack initiation lifetime using the Smith, Watson, and Topper (SWT) damage model. To analyse the fretting fatigue crack propagation part of the total lifetime, a 3D model is set-up to simulate the fatigue crack propagation using eXtended Finite Element Method (XFEM). A cubic spline description for crack geometry is used to characterize the evolving crack front, whose rate and three-dimensional growing shape is controlled by a crack propagation law. Eventually, the predicted total fatigue lifetimes are compared against experimental observations taken from literature [1].

\section{Theoretical background}

\subsection{Fatigue crack initiation}

To numerically estimate the number of cycles spent in the initiation phase, the SWT multiaxial fatigue criterion was used based on local stress and strain distributions. SWT is a local approach, meaning that it recognizes the localized nature of fatigue damage, and correlates a local damage parameter (e.g. strain, energy) with the number of cycles required to initiate a macroscopic crack.

In the lug joint which is subjected to cyclic external loads, the behaviour of material at the contact interface between the pin and the lug is best considered in terms of strain. Since fatigue damage is assessed directly in terms of local strain, this approach is also called the "local strain approach". A reasonable expected fatigue life, based on the initiation or formation of small macrocracks, can then be determined. The most well-known relations in this area are the proposals by Basquin [11], Coffin [13], Manson [12] and Morrow [13]:

$$
\begin{gathered}
\Delta \sigma / 2 \mathrm{E}=\Delta \varepsilon_{\mathrm{e}} / 2=\frac{\sigma_{\mathrm{f}}^{\prime}}{E}\left(2 \mathrm{~N}_{\mathrm{i}}\right)^{\mathrm{b}} \\
\Delta \varepsilon_{\mathrm{p}} / 2=\varepsilon_{f}^{\prime}\left(2 \mathrm{~N}_{\mathrm{i}}\right)^{\mathrm{c}} \\
\varepsilon_{a}=\Delta \varepsilon_{e} / 2+\Delta \varepsilon_{p} / 2=\frac{\sigma_{\mathrm{f}}^{\prime}}{E}\left(2 \mathrm{~N}_{\mathrm{i}}\right)^{\mathrm{b}}+\varepsilon_{f}^{\prime}\left(2 \mathrm{~N}_{\mathrm{i}}\right)^{\mathrm{c}}
\end{gathered}
$$

where $2 N_{i}$ is the number of reversals to local failure; $\Delta \varepsilon_{t}, \Delta \varepsilon_{e}$ and $\Delta \varepsilon_{p}$ are, respectively, the total, elastic and plastic strain ranges; $\Delta \sigma$ is the stress range and $E$ is the Young's modulus. The constants in these relations may be determined from fatigue tests on smooth specimens under strain-controlled conditions. These constants can be used to evaluate fatigue performance of different materials and can be defined as:

- $\sigma_{f}^{\prime}=$ Fatigue strength coefficient,

- $b=$ Fatigue strength exponent,

- $\varepsilon_{f}^{\prime}=$ Fatigue ductility coefficient,

- $\quad c=$ Fatigue ductility exponent.

\subsubsection{SWT fatigue damage model}

In this criterion, the fatigue damage parameter SWT is described as a stress and strain product and the critical plane is the plane where the normal strain range is maximum [14]. The SWT parameter proposes a suitable relationship that includes both the cyclic strain range and the maximum stress. The SWT parameter is used in the analysis of both proportionally and non-proportionally loaded components for materials that fail primarily due to mode I tensile cracking. The SWT parameter for multiaxial loading is based on the principal strain range, $\Delta \varepsilon_{1}$ and maximum stress on the principal strain range plane, $\sigma_{n, \max }$.The SWT fatigue damage parameter is defined as:

$$
\sigma_{n, \max }\left(\Delta \varepsilon_{1} / 2\right)=\frac{\sigma_{\mathrm{f}}^{\prime 2}}{E}\left(2 \mathrm{~N}_{\mathrm{i}}\right)^{2 \mathrm{~b}}+\varepsilon_{f}^{\prime} \sigma_{\mathrm{f}}^{\prime}\left(2 \mathrm{~N}_{\mathrm{i}}\right)^{\mathrm{c}+\mathrm{b}}
$$

\subsection{Fatigue crack propagation}

In terms of fatigue crack propagation analysis, the framework [15] based on extended finite element is used to calculate fatigue crack propagation lifetime under complex loading automatically.

\subsubsection{Extended finite element method}

XFEM was developed to relieve a local discontinuity by introducing enriched functions to the element, as shown in Figure 2. It solves the singularity problem by adding more integration points within elements instead of having to remesh and relax nodes. Due to this method, 
accuracy and computational time consumption are drastically improved.

A key development that facilitates the treatment of cracks in the XFEM analysis is the description of the crack geometry, because the mesh is not required to conform to the crack geometry. The level set method, which is a powerful numerical technique for analyzing and computing interface motion, fits naturally with the XFEM and makes it possible to model arbitrary crack growth without re-meshing. Figure 2 shows the schematic representation of an XFEM crack in a single mesh as reported by [16].

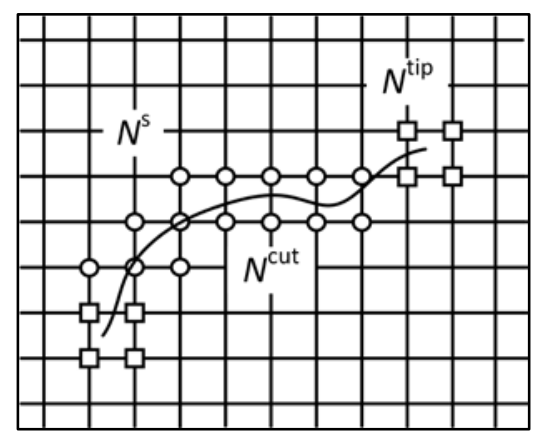

Fig. 2. Schematic of extended finite element method [16].

For the purpose of fracture analysis, the enrichment functions typically consist of near-tip asymptotic functions that capture the linear-elastic singularity around the crack tip and a discontinuous function that represents the jump in displacement across the crack surfaces. The approximation for a displacement vector function $u$ with the partition of unity enrichment is

$$
\begin{gathered}
\boldsymbol{u}=\sum_{i \in N^{S}} N_{i}(x) u_{i}+\sum_{i \in N^{c} u t} N_{i}(x) a_{i} H(x) \\
+\sum_{j} b_{j}^{i} B_{j}(x)
\end{gathered}
$$

where $N^{s}, N_{i}(x), N^{c u t}, H(x), N^{\text {tip }}$ and $B_{j}(x)$ are usual nodal elements, normal node functions, through crack elements, discontinuous jump functions, partial crack elements and crack tip functions, respectively.

\subsubsection{Automated framework for three-dimensional crack propagation}

The basic idea of the framework is using information of discrete stress intensity factors along the fatigue crack front to determine how it propagates (comprising both the amount and trajectory of crack growth). The framework consists of pre-processing, post-processing and analysis modules, communicating with ABAQUS, in Python programming language.

The pre-processing module establishes the model by constructing crack geometry, initializing material properties and defining boundary conditions and external load. The post-processing module extracts and processes discrete necessary data. The analysis module creates the simulation iteratively depending on the results generated in the previous increment. The extended finite element feature within ABAQUS is hereto utilized. Increment and direction of propagating crack front are calculated based on the crack propagation rate curve of the material and an out-plane direction criterion.

\subsubsection{Life prediction of fatigue crack propagation}

The stress intensity factor range can be expressed as a function of crack length. In this study a cubic spline interpolation function is used, as shown in in Figure 3. The total life of crack propagation can be calculated by summing up all amounts of cycles corresponding to the crack increments using Equations 6 and 7.

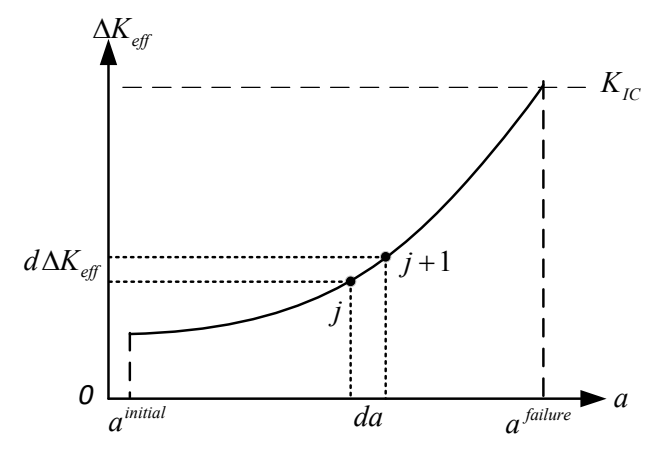

Fig. 3. Schematic of stress intensity factor versus the crack length growth rate.

$$
\begin{gathered}
d a / d N=C\left(\Delta K_{\text {eff }}\right)^{m} \\
N=\int_{a^{\text {initial }}}^{a^{\text {failure }}}\left(d a / C\left(\Delta K_{\text {eff }}\right)^{m}\right)
\end{gathered}
$$

\section{Numerical model and material}

\subsection{Finite Element Model}

2D and 3D models were developed to simulate the fretting fatigue crack initiation and propagation lifetimes using ABAQUS commercial software, respectively, as shown in Figures 4 and 5. 


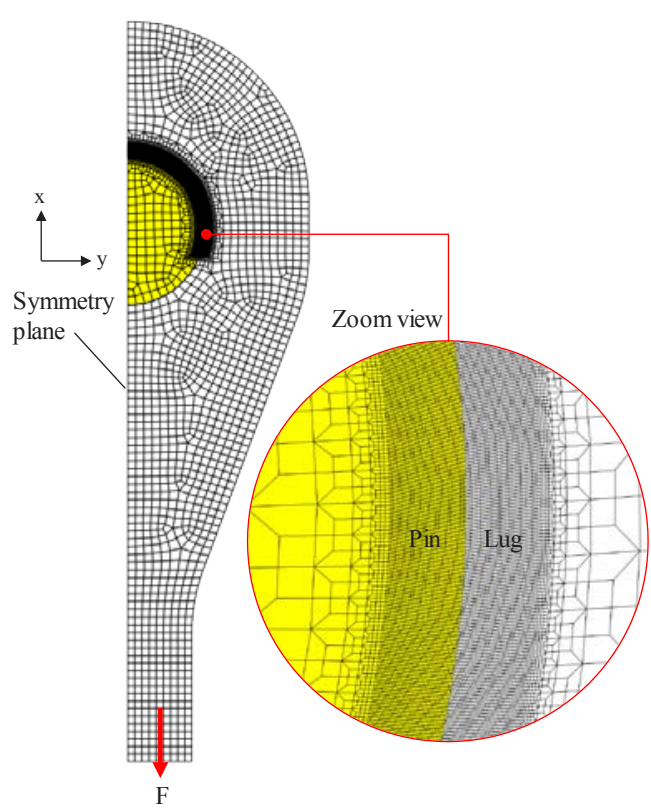

Fig. 4. 2D plane strain finite element model with a fine mesh at the contact interface between the pin and the lug.



Fig. 5. 3D Finite element model with relatively coarser mesh for inserting the XFEM crack to study the fatigue crack propagation lifetime in the pin/lug joint.

For 2D and 3D models, as shown in Figure 4 and 5, half and quarter of the lug geometry were simulated, respectively. The loading and boundary conditions for both models were selected based on the study published by S.Glodez et al. [1]. Five fatigue axial loads were applied ranging from $500 \mathrm{kN}$ to $880 \mathrm{kN}$ with loading ratio of 0.1 . The applied loads result in axial stresses in the cross section of the lug which are $333.33 \mathrm{MPa}, 400 \mathrm{MPa}$, 466.67MPa, 533.33MPa and 586.67MPa.

For the 2D model, a two-dimensional, plane strain, 4node (bilinear), quadrilateral, reduced integration element (CPE4R) was used. A mesh size of $0.1 \mathrm{~m} \times$ $0.1 \mathrm{~mm}$ was considered at the contact interface between the pin and the lug and decreased gradually far from the contact region, as depicted in Figure 4. The contact between the pin and the lug was defined using a masterslave algorithm. The outer surface of the pin was defined as a slave surface and the inner surface of the lug was defined as a master surface. A penalty formulation of friction was included in the contact pair to define the frictional behaviour of the connected parts. The contact was considered as lubricated, having a low friction coefficient of $\mu=0.05$.

For the 3D model, a three-dimensional, eight-node linear hexahedral continuum element (C3D8R) was used in order to mesh the lug component. A mesh size of 0.2 $\times 0.2 \times 0.2 \mathrm{~mm}^{3}$ was considered at the potential crack propagation regions and increased gradually away from the area of interest. Moreover, a rigid part was used to represent the pin.

\subsection{Material parameters}

In this study S1100Q HSS grade was used to analyse the fretting fatigue failure mechanism of the lug joint. Table 1 shows all material parameters that were used for simulating both $2 \mathrm{D}$ and $3 \mathrm{D}$ models, along with the parameters needed for estimating the fretting fatigue crack initiation and propagation lifetimes of the lug joint taken from the literature [1]

Table 1. Material properties of S1100Q HSS grade [1].

\begin{tabular}{|c|c|c|}
\hline Elastic modulus & $E[\mathrm{GPa}]$ & 194889 \\
\hline Poisson's ratio & $v[-]$ & 0.3 \\
\hline Yield stress & $\sigma_{y}[\mathrm{MPa}]$ & 1148 \\
\hline Ultimate stress & $\sigma_{u l t}[\mathrm{MPa}]$ & 1450 \\
\hline $\begin{array}{c}\text { Strength } \\
\text { coefficient }\end{array}$ & $K[\mathrm{MPa}]$ & 2272 \\
\hline $\begin{array}{c}\text { Strain-Hardening } \\
\text { exponent }\end{array}$ & $n[\mathrm{MPa}]$ & 0.109 \\
\hline \multicolumn{3}{|c|}{ Fatigue crack initiation parameters } \\
\hline $\begin{array}{l}\text { Fatigue strength } \\
\text { coefficient }\end{array}$ & $\sigma_{f}^{\prime}[\mathrm{MPa}]$ & 2076 \\
\hline $\begin{array}{l}\text { Fatigue ductility } \\
\text { coefficient }\end{array}$ & $\varepsilon_{f}^{\prime}[-]$ & 9.93 \\
\hline $\begin{array}{c}\text { Fatigue strength } \\
\text { exponent }\end{array}$ & $b[-]$ & -0.0997 \\
\hline $\begin{array}{c}\text { Fatigue ductility } \\
\text { exponent }\end{array}$ & $c[-]$ & -0.978 \\
\hline \multicolumn{3}{|c|}{ Fatigue crack propagation parameters } \\
\hline $\begin{array}{l}\text { Threshold stress } \\
\text { intensity factor }\end{array}$ & $\begin{array}{c}\Delta K_{t h} \\
{[M P a \sqrt{m m}]}\end{array}$ & 315 \\
\hline $\begin{array}{l}\text { Critical stress } \\
\text { intensity factor }\end{array}$ & $\begin{array}{c}K_{I C} \\
{[M P a \sqrt{m m}]}\end{array}$ & 2100 \\
\hline $\begin{array}{l}\text { Paris's law } \\
\text { coefficient }\end{array}$ & $\begin{array}{c}C \\
{[\mathrm{~mm} /(\mathrm{cycle} .} \\
M P a \sqrt{\mathrm{mm}})]\end{array}$ & $2.02 \times 10^{-11}$ \\
\hline $\begin{array}{c}\text { Paris 's Law } \\
\text { exponent }\end{array}$ & $m$ & 2.761 \\
\hline
\end{tabular}

\section{Result and discussion}

\subsection{Fretting Fatigue Stress Distribution}

Figure 6 shows the von Mises stress distribution of the pin/lug joint. Figure 7(a) to (d) show different stress distributions, which are normalized using the material's yield stress, plotted versus the normalized contact 
distance. Figures 7(e) and (f) plot the slip amplitude and the normalized fretting fatigue damage parameter (FFD) at the contact interface for all applied axial loads.

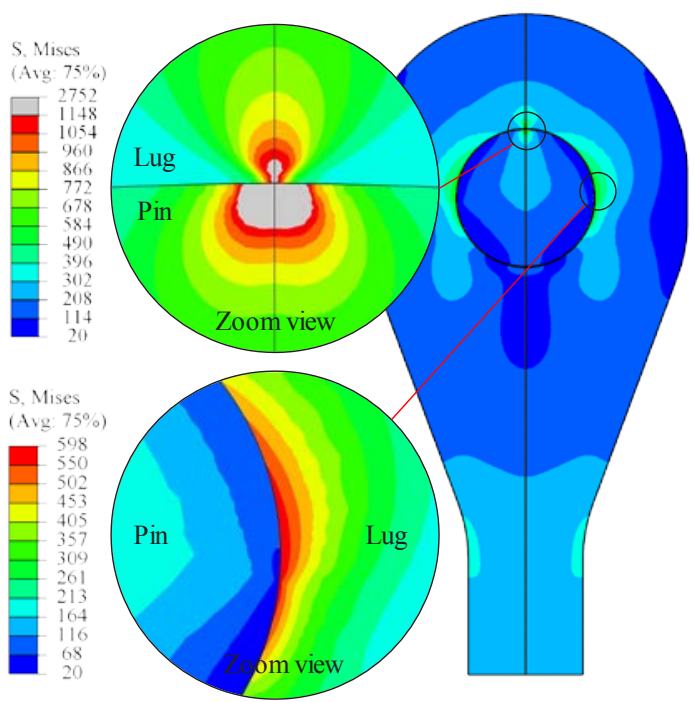

Fig. 6. Von Mises stress distribution at maximum applied load of $500 \mathrm{kN}\left(\sigma_{\text {axial }} \approx 333 \mathrm{MPa}\right)$.



(a)

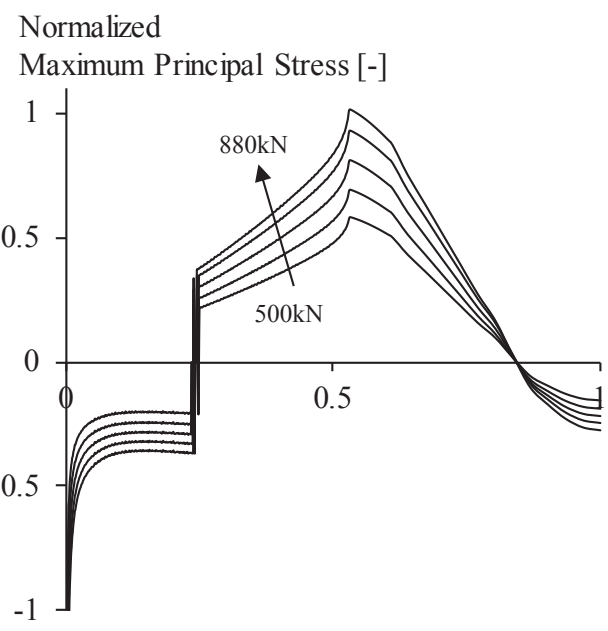

Normalized distance [-]

(b)

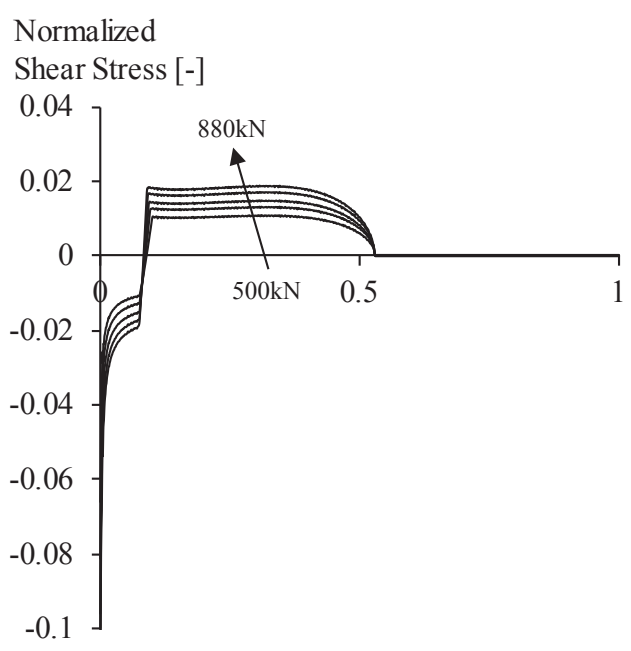

Normalized distance [-]

(c)

\section{Normalized}

Tangential Stress [-]



Normalized distance [-]

(d)

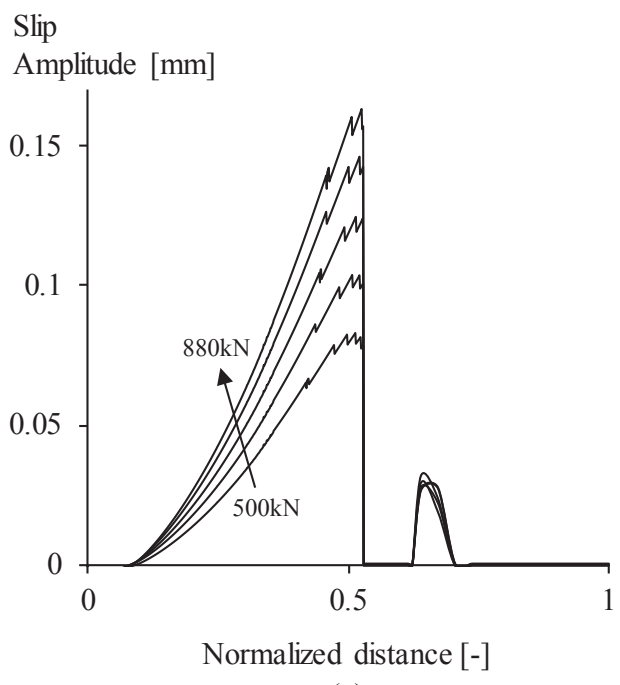

(e) 


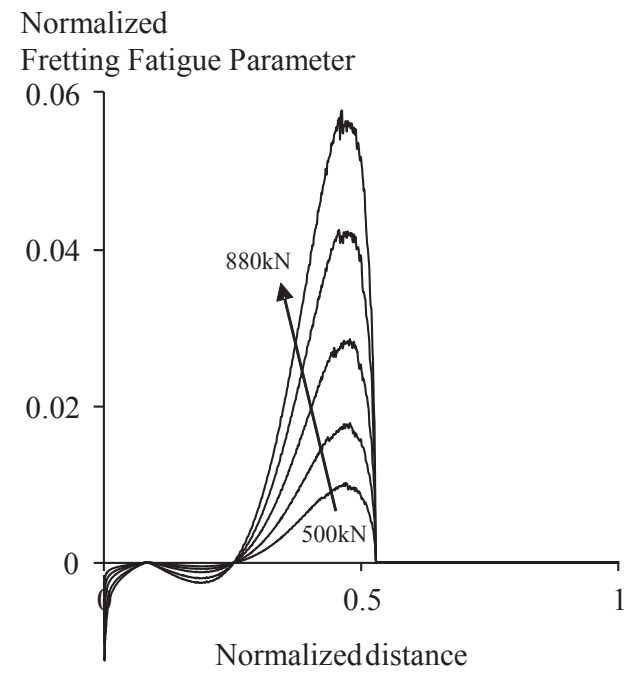

(f)

Fig. 7. Different normalized stress distributions plotted versus the normalized distance. (a) contact pressure, (b) maximum principal stress, (c) shear and (c) tangential stresses along with (e) slip amplitude. (f) the normalized fretting fatigue parameter (FFD) at the contact interface.

As can be seen from Figures 6 and 7(a), the maximum contact pressure is located at the 0 position (see Figure 7). However, the fatigue crack initiates almost at the centre of the contact between the pin and the lug, as illustrated in Figures 6 and 7(b). Figure 7(c) shows that the shear stress at the contact interface increases by raising the applied axial fatigue load from $500 \mathrm{kN}$ to $880 \mathrm{kN}$. Nonetheless, as expected because of the low friction coefficient, the magnitude of the shear stress is low compared to other stress values such as contact pressure, maximum principal and tangential stress $\left(\sigma_{x x}\right)$ plotted in Figures 7(a), (b) and (d). This low shear stress results in higher slip amplitude, as shown in Figure 7(e), which is more damaging concerning the fatigue damage accumulation according to the fretting map reported by Vingsbo and Söderberg [17].

Figure 7(f) plots the fretting fatigue damage parameter (FFD) at the contact interface for all applied stress levels. The FFD parameter is a relationship between fretting damage and stress distribution at the contact interface, as first introduced by Ruiz et al. [18]. This parameter is a measure of the frictional work at contact interface which can be written as; $\tau$. $\delta$, where $\tau$ is local value of frictional shear stress and $\delta$ is a local slip amplitude within the contact region. To take into consideration the effect of applied axial fatigue load, the axial stress at the contact interface along the loading direction, i.e. tangential stress $\left(\sigma_{x x}\right)$ is multiplied by the frictional work, which results in the FFD parameter. In this study the FFD parameter was normalized against the product of yield stress $\left(\sigma_{y}\right)$ and lug hole radius $(R)$. The location of maximum FFD is near the centre of the hole for all applied stress levels, where the initial fatigue crack is expected to be initiated, as indicated in Figure 7(f).

\subsection{Lifetime Estimation}

To calculate the fretting fatigue lifetime, the stress and strain were extracted at the maximum location of FFD parameter along the contact interface for all applied stress levels. Then the SWT parameter in Equation 4 was calculated by means of a Python script using the principal strain range, $\Delta \varepsilon_{1}$ and maximum stress on the principal strain range plane, $\sigma_{n, \max }$. Eventually, the fretting fatigue lifetimes of the pin/lug joint were estimated for all applied axial loads.

Concerning the fatigue crack propagation, an initial fatigue elliptical crack with two axes equal to $0.5 \mathrm{~mm}$ were imported in the three dimensional FE model, as shown schematically in Figure 5. A pre-defined crack propagation increment was set to $0.5 \mathrm{~mm}$. Figure 8 shows the initial XFEM crack inserted in the 3D model and the in-plane fatigue crack propagation lines at a low stress level. Using the approach elaborated in section 2.2.3, the fatigue crack propagation lifetimes were calculated for all applied load levels.

Eventually, the predicted fatigue crack initiation and propagation lifetimes were added for each applied stress level to estimate the total lifetime of the pin/lug connection subjected to the fretting fatigue loading conditions. Figure 9 shows the axial stress versus the number of cycles to final rupture for all applied fatigue load levels. The predicted fretting fatigue lifetime at high stress level, i.e. $880 \mathrm{kN}$ axial fatigue load, was compared against the observed experimental data reported in [1]. The figure shows that the estimated results at high stress level are in good agreement with the measured experimental lifetime.

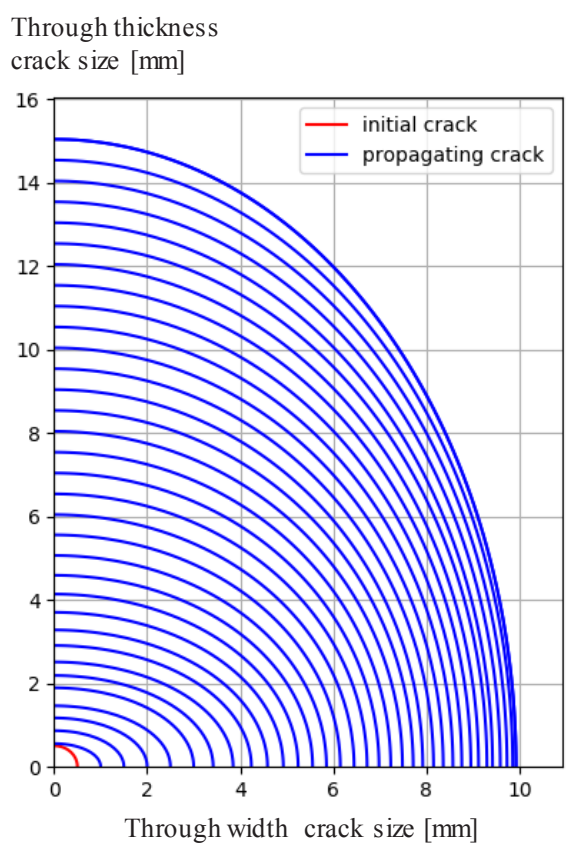

Fig. 8. In-plane fatigue crack propagation line at a low stress level $\left(\sigma_{\text {axial }}=200 \mathrm{MPa}\right)$. 


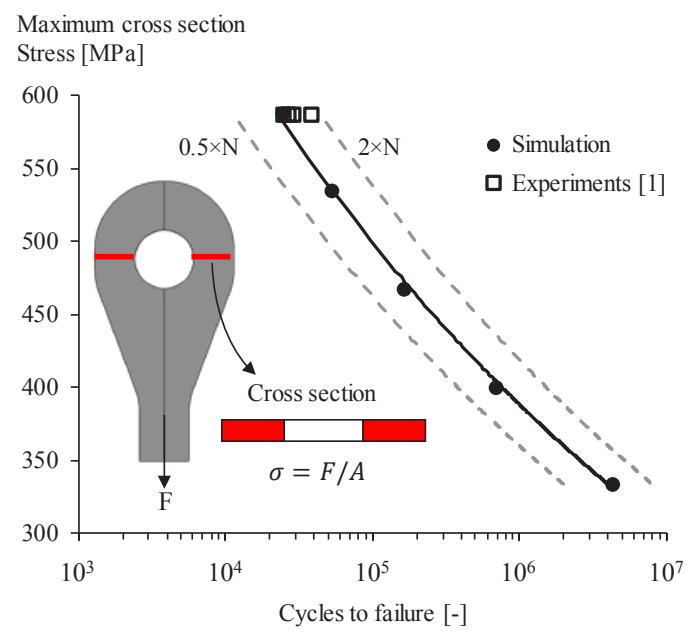

Fig. 9. Cross section stresses versus estimated lifetime of a $\mathrm{pin} /$ lug joint subjected to fretting fatigue lifetime. The predicted results at high stress level were compared against the observed data from literature [1].

\section{Conclusion}

In this study, the fretting fatigue crack initiation and propagation in a pin/lug joint are simulated using a multiaxial fatigue damage criterion and linear-elastic fracture mechanics, respectively. First a 2D finite element model was developed for obtaining stress and strain distributions at the contact interface in the pin/lug joint. Using the extracted data, the fretting fatigue failure parameters were analysed. Next, the obtained stress and strain were used to estimate the fatigue crack initiation lifetime using the multiaxial SWT damage model. Next, a 3D model was set-up to model the fatigue crack propagation using eXtended Finite Element Method (XFEM). A cubic spline description for crack geometry was used to characterize the evolving crack front, whose rate and three-dimensional shape of growth was controlled by the crack propagation law.

Eventually, the predicted total fatigue lifetimes were compared against experimental observations taken from literature. Form the predicted results it could be concluded that the fretting fatigue mechanism is the dominated failure mechanism in a pin/lug joint subjected to cyclic loading conditions. A good correlation was found between the estimated results and the observed experimental results from the literature.

\section{References}

1. S. Glodež, M. Knez, N. Jezernik, and J. S. Kramberger, Eng. Failure Anal. 16, p. 2348-2356 (2009).

2. R. Hojjati Talemi, Numerical modelling techniques for fretting fatigue crack initiation and propagation. (Ghent University, 2014).

3. R. Hojjati Talemi, A. Zahedi, and P. De Baets, Int. J. Fatigue 73 p. 58-65 (2015).

4. A. Ferjaoui, T. Yue, M.A. Wahab, R. HojjatiTalemi,
Int. J. Fatigue 73 p.66-67 (2015)

5. C. Jiménez-Peña, R. Hojjati Talemi, B. Rossi, D. Debruyne, Tribol. Int. 108 p. 128-140 (2017).

6. D.A. Hills, Wear, 175 p.107-113 (1994).

7. R.H. Talemi, M.A. Wahab, and P. De Baets, J. Phys.: Conf. Ser. 305 p. 012061 (2011).

8. R. Hojjati-Talemi, M.A. Wahab, and P. De Baets, Proc. Inst. Mech. Eng., Part J 228 p. 470-479 (2014).

9. J. De Pauw, W. De Waele, R. Hojjati-Talemi, and P. De Baets, Int. J. Solids Struct. 51 p. 3058-3066 (2014).

10. R.H Talemi, Numerical measures of nonproportionality degree in incomplete contact subjected to fretting fatigue loading. Theor. Appl. Fract. Mech. 90 p. 33-42 (2017).

11. O. Basquin, The exponential law of endurance tests in Proc. ASTM (1910).

12. Jr. Coffin, A study of the effects of cyclic thermal stresses on a ductile metal, trans. ASME 76 p. 931950 (1954).

13. J. Morrow, Cyclic plastic strain energy and fatigue of metals, in Internal friction, damping, and cyclic plasticity (ASTM International 1965).

14. K.N. Smith, P. Watson, and T.H. Topper, Journal of Materials 4 p. 767-778 (1970).

15. J. Zhang, S. Hertelé, N. Micone, and W. De Waele, Modelling framework for 3D fatigue crack propagation in welds of offshore steel structures. in International Conference on Integrity: Reliability: Failure INEGI/FEUP (2016).

16. N. Moës, J. Dolbow, and T. Belytschko, Int. J. Numer. Meth. Eng. 46 p. 131-150 1999.

17. O. Vingsbo, and S. Söderberg, Wear 126 p. 131-147 (1988).

18. C. Ruiz, P.H.B. Boddington, and K.C. Chen, Exp. Mech. 24 p. 208-217 (1984). 